\title{
Estudo crítico da nova resolução da ANAC para concessão e renovação de habilitação de tipo
}

\author{
Analysis of ANAC's New Resolution for Concession and \\ Renewal of Type Rating
}
Análisis de la Nueva Resolución de la ANAC para Concesión y Renovación de Habilitación de Tipo

\section{Analyse de la nouvelle résolution ANAC pour la concession et le renouvellement de qualification de type}

Rodrigo Rodrigues de Carvalho Musy (OrcID) musyrodrigo@hotmail. com Instituto Tecnológico de Aeronáutica (ITA)

\section{João César Moura}

Mota (OrcID) motagpel@gmail.com Universidade Federal do Ceará (UFC)

\section{Marcus Vinícius} Garcia Pacobahyba Pessanha (OrcID) pacobahybabq86@ gmail.com Instituto Tecnológico de Aeronáutica (ITA)

\begin{abstract}
Resumo
O presente trabalho tem por objetivo realizar um estudo crítico sobre os novos procedimentos exigidos pela Agência Nacional de Aviação Civil (ANAC) para a concessão e/ou renovação de habilitação de tipo no Brasil. São descritos e analisados os impactos causados na aviação geral a partir da nova regulamentação, bem como apresentam-se procedimentos alternativos ou provisórios para a concessão e a renovação da habilitação de tipo, os quais podem ser úteis para uma proposição de normas em longo termo.
\end{abstract}

Palavras-chave: ANAC. Habilitação de tipo. Aviação geral.

\section{Abstract}

The present work aims to perform a critical analysis of the new procedures required by the Agência Nacional de Aviação Civil - ANAC for the concession and/or renewal of Type Rating in Brazil. The impacts caused in general aviation by the new regulations are described and analyzed, as well as alternative or provisional procedures for the granting and renewal of type ratingl, which may be useful for proposing long-term standards.

Keywords: ANAC. Type rating. General aviation.

\section{Resumen}

Este trabajo objetiva analizar críticamente los nuevos procedimientos exigidos por la Agencia Nacional de Aviación Civil para la concesión y/o renovación de la Habilitación de Tipo en Brasil. Son descriptos y analizados los impactos causados en la aviación general a partir de la nueva regulación, así como son presentados procedimientos alternativos o provisionales para la concesión y la renovación de la Habilitación de Tipo, los cuales pueden ser útiles para una proposición de normas de largo plazo.

Palabras-clave: ANAC. Habilitación de tipo. Aviación general.

\section{Résumé}

Le présent travail a pour objectif de réaliser une analyse critique des nouvelles procédures requises par l'Agence Nationale d'Aviation Civile brésilienne pour la concession et / ou le renouvellement de qualification de types au Brésil. Les impacts causés par la nouvelle résolution sur l'aviation générale sont décrits et analysés, ainsi que les procédures alternatives ou provisoires pour l'a concession et le renouvellement de Qualification de Type, lesquels peuvent être utiles pour proposer des normes à long terme.

Mots-clés: ANAC. Qualification de type. Aviation générale. 


\section{Introdução}

Como país signatário da International Civil Aviation Organization (ICAO), o Brasil deve seguir os procedimentos para a emissão de licenças e habilitações de pilotos e tripulantes conforme preconiza o Anexo 1 da ICAO.

AAgência Nacional de Aviação Civil (ANAC) é o órgão responsável por regulamentar os procedimentos e as normas da aviação civil brasileira, constantes do Regulamento Brasileiro de Aviação Civil 61 (RBAC) [1] o qual reflete os requisitos do Anexo 1 da ICAO.

As normas e os procedimentos referentes à habilitação de tipo foram publicados na Instrução Suplementar - IS n. ${ }^{\circ}$ 61-005 [2], que indicam as instruções para a realização dos treinamentos de solo e de voo visando à concessão e à revalidação da habilitação de tipo, de acordo com a Subparte K do [1]. Concomitantemente, foi publicada uma Lista de Treinamentos de Tipo aprovados pela ANAC, cuja última revisão é recente [4].

Com a finalidade de auxiliar na compreensão sobre o assunto e de, posteriormente, propor um diálogo com a ANAC sobre uma possível adequação à norma vigente, procedeu-se, neste artigo, a uma análise qualitativa a respeito da legislação de que trata o tema.

Na seção 2 classifica-se a aviação geral, em especial a aviação executiva, e analisa-se a composição da frota de aeronaves e a formação profissional dos pilotos no Brasil. Na seção 3 define-se a habilitação de tipo e apresentam-se os regulamentos e os procedimentos para a concessão e a revalidação da mesma. $\mathrm{Na}$ seção 4 são feitas análises sobre as principais mudanças realizadas através da [2] e os impactos causados na aviação geral.

A seção 5 apresenta procedimentos alternativos para a concessão e a revalidação da habilitação de tipo, os quais se tornam economicamente viáveis, sem perda de qualidade do ponto de vista do operador aeronáutico, favorecendo o investimento para a manutenção e a aquisição de novas aeronaves, entre outros benefícios. Por fim, a seção 6 apresenta a conclusão do trabalho e suas perspectivas no cenário aeronáutico brasileiro.

\section{Aviação executiva no Brasil}

\subsection{Histórico e panorama}

Antes de discorrer sobre a aviação executiva, é necessário delimitar a classificação existente para a aviação. A aviação divide-se em aviação militar e aviação civil. Por sua vez, a aviação civil é dividida em aviação comercial, aviação experimental e aviação geral (Fig. 1).

Figura 1 - Classificação da Aviação

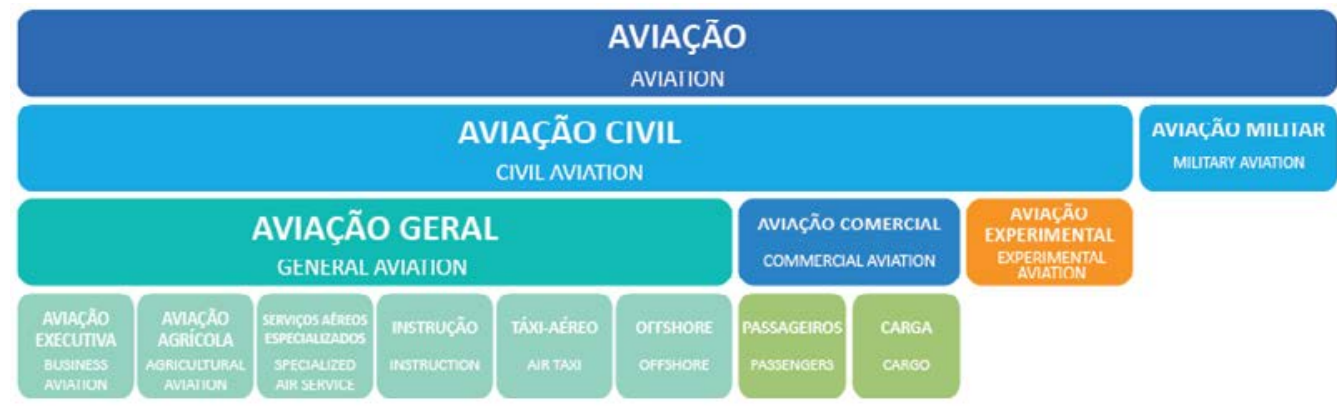

Fonte: ABAG, 2017

Atualmente, no Brasil, consideramos aviação comercial a atividade do serviço de transporte aéreo público, regular e não regular, doméstico ou internacional, de passageiros ou de cargas, realizadas por empresas especializadas e autorizadas para executar esse serviço. A aviação experimental, por sua vez, compreende 
aeronaves com fins experimentais e desportivos. Em se tratando de construção, uma aeronave experimental difere de uma aeronave certificada por não passar por todos os processos de testes e certificações de segurança regulamentados. Por causa dessas restrições, normalmente, aeronaves experimentais são utilizadas para lazer ou para experimentar novos conceitos. Já a aviação geral compreende todos os serviços aéreos não operados por companhias aéreas, empresas de voos charter ou pelos militares. Essas operações consistem em: negócios, turismo, serviços de busca e resgate, treinamento, recreação, serviço aéreo ambulatorial e uma variedade de outros usos que completam o sistema mundial de transporte aéreo [8].

A parte da aviação geral destinada ao ramo de negócios é denominada aviação executiva, na qual uma empresa ou um proprietário utiliza sua aeronave como meio multiplicador dos negócios de sua empresa. A aviação executiva é composta por helicópteros e aviões. Os helicópteros têm limitação de velocidade, seus motores não permitem que ultrapassem $480 \mathrm{~km} / \mathrm{h}$ e, por isso, não são usados para o transporte aéreo de linhas regulares, mas são amplamente utilizados como transporte aéreo executivo, disputando espaço com pequenos aviões a jato - os "jatinhos" - e ambos têm um mercado específico [8].

Notadamente, o uso da aviação executiva permite que novas conexões dinamizem os negócios por meio da rapidez e eficiência, o que acelera o processo de investimento e a melhoria das relações comerciais. Por isso, a capacidade de fazer negócios mais rapidamente e mais longe da cidade-base onde se localiza a sede é o principal benefício da aviação executiva para os governos federal e estadual, para as empresas brasileiras e, em última instância, para toda a economia do país. Por flexibilidade, a gama de destinos que podem ser alcançados por uma aeronave da aviação executiva amplia exponencialmente as opções em relação aos limites das rotas regulares, sendo que seus usuários podem combinar vários destinos em uma fração do tempo gasto em relação à rede da aviação comercial. Com o mesmo número de horas, os passageiros alcançam mais objetivos, gerando valioso ganho de produtividade. Além disso, os usuários da aviação executiva têm acesso a um portfólio variado de aeronaves que se adapta às suas necessidades, seja um pequeno avião monomotor, seja um helicóptero turboélice com diversos assentos. Essas aeronaves que podem ser utilizadas para transportar uma única pessoa ou uma equipe inteira para vários destinos ao longo de vários dias e com instalações de escritório a bordo [8].

A aviação executiva foi iniciada em 1925. A Los Angeles San Diego Air Lines utilizou um Douglas Cloudster para levar passageiros da costa oeste a costa leste dos Estados Unidos. Essa modalidade de aviação desenvolveu-se a partir da década de 1930 e, desde então, tornou-se um segmento do mercado que se desenvolve distante dos parâmetros do transporte aéreo regular, a conhecida aviação comercial [8].

No Brasil, a aviação executiva desempenha importantes atividades, tais como:

a) transporte de pessoas e cargas de alto valor agregado para o interior do país, onde a aviação comercial regular não atua;

b) transporte a locais inacessíveis, principalmente nas áreas de floresta;

c) transporte de pessoas e materiais às plataformas de extração de petróleo em alto mar;

d) transporte de suprimentos a garimpos e frentes de construção de estradas;

e) remoção de enfermos e de acidentados para centros hospitalares mais desenvolvidos.

O Brasil, com uma população de 200 milhões de habitantes em um território com pouco mais de 8,5 milhões de quilômetro quadrados, tem características notoriamente singulares. O Norte é massivamente ocupado pelo bioma amazônico, que representa $49 \%$ do território brasileiro, sendo cortado por rios, densamente ocupado pela floresta e com chuvas abundantes, é um território amplo, onde a melhor forma de se ganhar tempo no transporte é o avião. Dessa forma, as operações de aviação geral desempenham um papel crucial no atendimento de demandas bem específicas da região. O Centro-Oeste, com pouco mais de 1,6 milhões de quilômetros quadrados, é a região de menor densidade populacional do país, com longas distâncias entre os centros urbanos e áreas rurais, com forte transformação do cerrado em terras produtivas para o pastoreio e agricultura. Nos anos recentes, com o grande crescimento da atividade agrícola, as operações da aviação executiva passaram a atender a um conjunto de necessidades muito amplo, garantindo a mobilidade de 
formadores de políticas públicas, produtores rurais, industriais, empresários e da população em busca de centros de serviços, como hospitais de aglomerados urbanos melhor aparelhados [8].

O Nordeste, composto por estados com características físicas bastante diferentes entre si, área superior a 1,5 milhões de quilômetros quadrados e com a maior área de costa marítima brasileira, apresentou, nos últimos anos, importante crescimento da renda per capita, o que tem atraído investimentos de diversos segmentos, tais como: infraestrutura, hotelaria, redes de varejo, redes de ensino, empresas de serviços, financeiras, setores que encontram na aviação executiva a flexibilidade e a agilidade para realizar a interconexão entre importantes capitais nordestinas e o interior, ou de realizar a interconexão com zonas geográficas distintas, como as regiões Sudeste e Sul do Brasil [8].

O forte crescimento da aviação geral tem contribuído para suportar as atividades de outros setores e no auxílio de populações locais. Contudo, os ambientes regulatórios e técnicos em que o setor opera, aliados a uma decisão consciente por parte dos operadores para desenvolver o talento local, têm estimulado o desenvolvimento regional de colaboradores para atividades como manutenção, treinamento e serviços de hospitalidade, por isso a aviação executiva cria alavancas econômicas positivas para a geração de empregos nas imediações do aeroporto por ela atendido [8].

Por sua vez, as regiões Sul e Sudeste apresentam importante concentração de aeroportos que atendem à aviação geral, e alguns com atividades exclusivas para o atendimento das operações de desenvolvimento, pesquisa e manutenção de grandes líderes do setor. Grandes empresas procuram nessas regiões garantir que a sede de seus escritórios esteja nas cercanias de aeroportos, tais como Campo de Marte, Bacacheri, Jacarepaguá e Pampulha. Nesse sentido, os operadores da aviação geral afirmam que seus clientes de uso intensivo procuram ter seus escritórios e atividades nas proximidades dos aeródromos, o que sugere que a indisponibilidade de aeródromos afasta investidores de alto potencial. Essas operações são utilizadas, em geral, para o transporte de pessoal entre instalações de varejo, produção industrial ou agrícola e sedes corporativas, com uma eficiência que não pode ser alcançada através de outros modais [8].

\subsection{A frota brasileira}

O Brasil possui a $2^{\mathrm{a}}$ maior frota de aeronaves executivas, atrás somente dos Estados Unidos da América (EUA), e é o $3^{\circ}$ país que mais produz essas aeronaves. À frente da Embraer só estão a canadense Bombardier e a americana Cessna. As aeronaves executivas responderam, em 2013, por $25 \%$ do faturamento da Embraer. Os Estados Unidos estão no topo da lista de compradores da Embraer, com 40\% dos 630 jatos executivos brasileiros em operação no mundo atualmente. O Brasil fica em segundo lugar, com $20 \%$, seguido por GrãBretanha, Alemanha e Emirados Árabes Unidos [10].

Composta por 21.905 aeronaves em 2016, a frota brasileira de aviação pode ser classificada nas seguintes categorias de registro: 5.516 aeronaves na categoria experimental -PET (25\%); 10.019 na categoria privadoTPP (46\%); 1.479 na categoria táxi aéreo-TPX (7\%); 650 na categoria transporte público regular-TPR (3\%); 1.915 instrução privada-PRI (9\%) e 2.326 em outras categorias (10\%) [6].

Do total acima elencado, há 1.445 aeronaves à reação - a jato-, sendo 521 pertencentes à categoria transporte público regular, ou seja, à aviação comercial, mais 762 no registro privado, e as demais pertencentes ao táxi aéreo [6].

Na Figura 2 pode-se observar os percentuais de distribuição da frota por categoria de registro. 
Figura 2 - Distribuição da frota brasileira

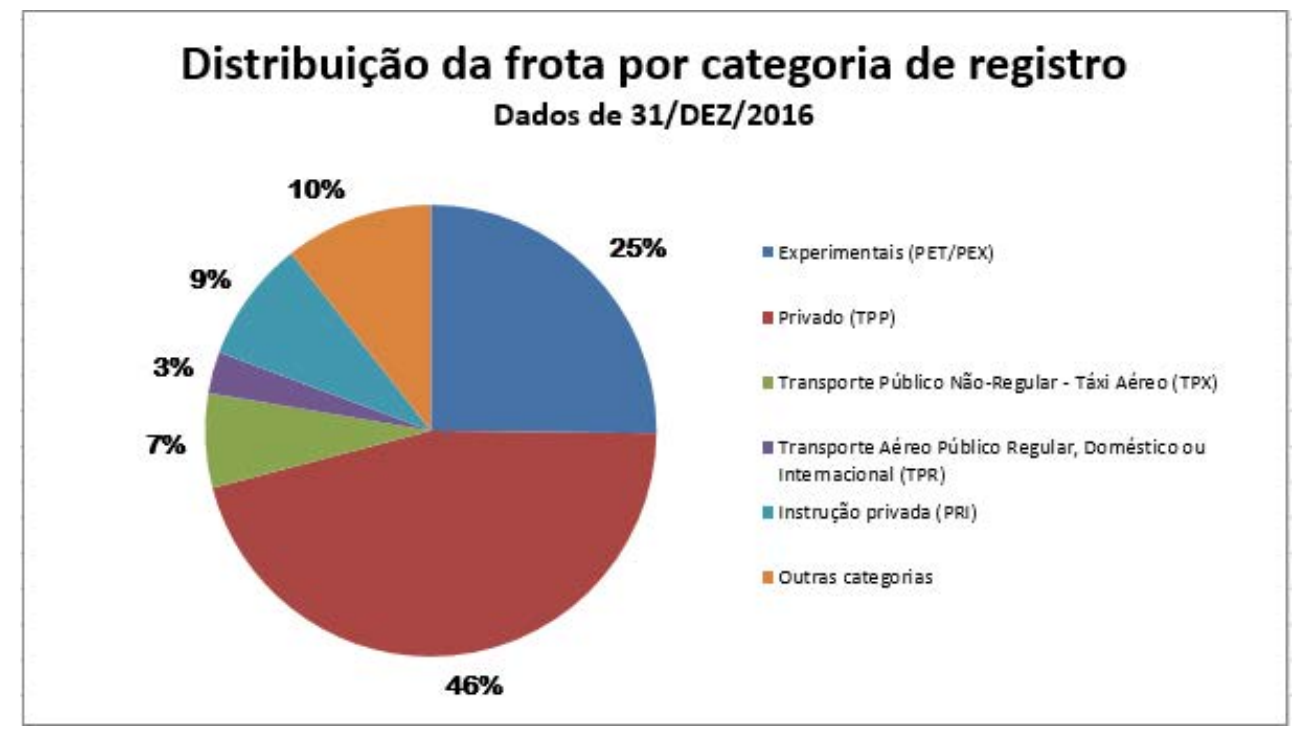

Fonte: ANAC, 2018.

Considerando-se o número de 762 aeronaves a jato sob a categoria de registro privado, infere-se que há uma demanda latente para a realização do treinamento anual obrigatório, em território nacional, de acordo com o Regulamento Brasileiro de Aviação Civil n. ${ }^{\circ} 61$ (RBAC 61) e a Instrução Suplementar n. ${ }^{\circ}$ 61-005, revisão A (IS 61-005A), haja vista a inexistência de Centros de Treinamento, conforme exposição no item seguinte. Dentre esse total de aeronaves, segundo o Registro Aeronáutico Brasileiro (RAB), deve-se destacar a expressiva quantidade de 161 aeronaves do modelo Cessna 525; 93 aeronaves do modelo Cessna 560; 89 aeronaves do modelo Cessna 550; 119 modelo Embraer E500; e 66 modelo Embraer E505. Somente estes dois últimos, modelos da Embraer, possuem o Centro de Treinamento no Brasil, na cidade de Guarulhos, São Paulo [6].

Já a frota de helicópteros é composta por 2.526 aeronaves, sendo 1.074 (43\%) equipadas com turbinas monomotores, 768 (30\%) com motores convencionais e $684(27 \%)$ com turbinas bimotores. Destaca-se a quantidade de 361 helicópteros modelo AS-350 Esquilo, 460 unidades do modelo R44 Robison e 137 helicópteros AW109 Agusta, respectivamente equipados com turbina monomotor, motor convencional e turbina bimotor (Fig. 3).

Figura 3 - Frota de helicópteros no Brasil em 2015

Motor convencional
768 helicópteros
Principais aeronaves
- $36 \rightarrow$ Schweizer
- $181 \rightarrow \mathrm{R} 22$
- $460 \rightarrow \mathrm{R} 44$
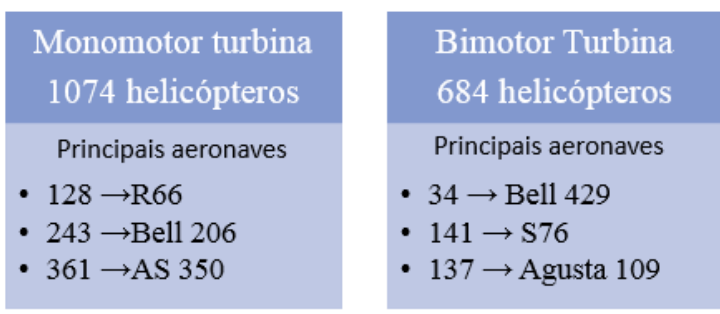

Participação na frota brasileira

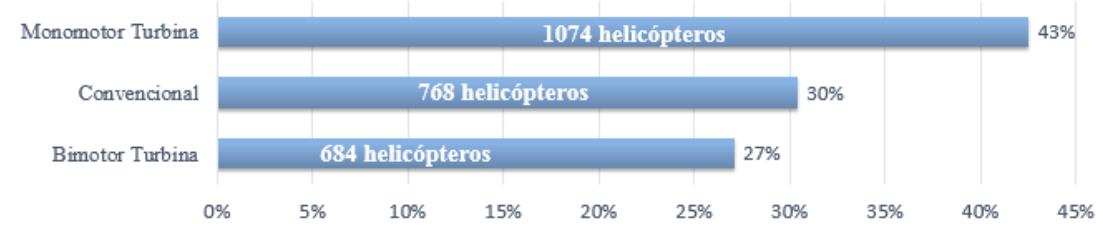

Fonte: ANAC, 2015. 


\section{Habilitação de tipo}

Segundo o RBAC n. ${ }^{\circ} 61$, o termo habilitação significa uma autorização associada a uma licença ou a um certificado, na qual são especificadas as qualificações e respectivas validades, condições especiais de operação e as respectivas atribuições e restrições relativas ao exercício das prerrogativas da licença ou certificado respectivo. Os principais tipos de habilitação são: habilitação de tipo, habilitação de voo por instrumentos, habilitação de instrutor de voo e habilitação de categoria e de classe.

De acordo com o RBAC n. ${ }^{\circ}$ 61, o item 61.3 aborda as condições relativas à utilização de licenças, certificados e habilitações de piloto: "só pode atuar como piloto em comando ou segundo em comando (...) uma licença/certificado de piloto com suas habilitações válidas...".

As habilitações são divididas segundo a categoria, classe, tipo e operação, conforme descrito em [1], no item 61.5 , o qual é o objeto fim deste estudo.

De acordo com o RBAC n. ${ }^{\circ} 61$, item 61.5:

(3) habilitações de tipo: são averbadas nas licenças de pilotos nos seguintes casos:

(i) aeronaves certificadas para operação com tripulação mínima de 2 (dois) pilotos;

(ii) aeronaves com peso máximo de decolagem aprovado superior a $5.670 \mathrm{~kg}(12.500 \mathrm{lb})$, exceto balões livres e dirigíveis;

(iii) aviões com motor a reação;

(iv) aeronaves de sustentação por potência; e

(v) para qualquer outra aeronave, sempre que considerado necessário pela ANAC

A habilitação de tipo é uma habilitação exigida para a operação de aeronaves complexas que exigem do piloto um treinamento específico para a operação correta e segura. Devido à complexidade da operação, a Habilitação de Tipo tem validade de 12 meses, o que obriga, com razoável frequência, a renovação do treinamento para a manutenção da qualificação operacional e do aumento da segurança das operações.

Para melhor compreensão, definem-se os conceitos de licença e habilitação, de acordo com o RBAC n. ${ }^{\circ}$ 61: "Licença significa o documento emitido pela ANAC que formaliza a certificação de uma pessoa para atuar em operações aéreas civis, a partir do cumprimento de requisitos de idade, grau de instrução, aptidão psicofísica, conhecimentos teóricos, instrução de voo, experiência e proficiência, verificados de acordo com as funções, limitações e prerrogativas pertinentes à referida licença". As principais licenças são: Piloto Privado de Aeronaves (PPR), Piloto Comercial de Aeronaves (PCA), Piloto de Linha Aérea (PLA), Piloto Privado de Helicópteros (PPH), Piloto Comercial de Helicópteros (PCH) e Piloto de Linha Aérea de Helicópteros (PLH).

A seguir, serão descritos e comentados os procedimentos para a concessão e a renovação da Habilitação de Tipo que se encontram na Subparte K do RBAC n. ${ }^{\circ} 61$ [1] e na IS 61-005 [2].

\section{Concessão e renovação da habilitação de tipo}

A Subparte $\mathrm{K}$ do RBAC $n .^{\circ} 61$ trata sobre a Habilitação de Tipo e estabelece os requisitos para a concessão e a revalidação para pilotos de avião, helicóptero, dirigível e aeronave de sustentação por potência, bem como descreve as prerrogativas e as condições para o exercício das funções inerentes à Habilitação de Tipo.

Para a sua concessão, o candidato deve ser aprovado em exame de conhecimento teórico da ANAC referente ao Piloto de Linha Aérea (PLA) [1], bem como no exame teórico da ANAC de regulamentos aeronáuticos sobre regras de voo visual (VFR, do inglês Visual Flight Rules) ou regras de voo por instrumentos (IFR, do inglês Instrument Flight Rules) [1], conforme aplicável à certificação da aeronave. De acordo com o item 61.213 [1] tanto o treinamento de solo quanto o treinamento de voo devem ser realizados em um Centro de Treinamento de Aviação Civil (CTAC), através de um programa de treinamento aprovado pela ANAC e, o exame de proficiência para a obtenção da Habilitação de Tipo, pode ser realizado em aeronave ou dispositivo de treinamento para simulação de voo qualificado ou validado pela ANAC [1]. 
Para a revalidação, conforme o item 61.215 [1], o candidato também deve realizar os treinamentos de solo e de voo em um CTAC certificado ou validado pela ANAC e deve ser aprovado em exame de proficiência para a revalidação da Habilitação, que pode ser realizado em aeronave ou dispositivo de treinamento para simulação de voo qualificado ou validado pela ANAC [1]. Esta mudança, que entrou em vigor a partir de 01 de janeiro de 2017 [4], será analisada e discutida nas seções 4 e 5 deste artigo.

Na subseção seguinte apresenta-se a Instrução Suplementar (IS) 61-005 [2], a qual complementa o conteúdo de [1], e que trata dos programas de treinamento e dos CTACs acreditados pela ANAC.

\subsection{A Instrução suplementar 61-005 revisão A (IS 61-005A)}

A IS 61-005A [2] estabelece instruções sobre o treinamento requerido para a concessão e revalidação de Habilitação de Tipo, complementando as normas do RBAC n. ${ }^{\circ} 61$ subparte K [1], referida no item anterior. O termo Habilitação de Tipo é uma habilitação específica para poder atuar como tripulante em cada aeronave que se pretenda voar. Se o piloto for voar uma aeronave Boeing 737, ele deve ter a habilitação B737; se o piloto for voar uma aeronave Boeing 767, ele deve ter a habilitação B767, apesar de as aeronaves serem do mesmo fabricante. Para cada Tipo (modelo) de aeronave é exigida uma Habilitação de Tipo específica.

Destaque-se que, o item 4 da Instrução Suplementar observa: “...o treinamento para a concessão e a revalidação de Habilitação de Tipo só pode ser realizado fora de tais entidades se, na data em que o candidato iniciar o treinamento, não existir entidade certificada ou validada que ministre o curso para o tipo de aeronave em que o candidato pretenda obter ou revalidar sua habilitação...", conforme a Lista de Treinamentos de Tipo, aprovada pela ANAC, disponível na sua página na internet [4].

Analisando a citada Lista, cuja última revisão está em [4], pode-se destacar que, no Brasil, há somente um CTAC homologado para o treinamento de um tipo de aeronave da Embraer, o Phenom 100/300, localizado em Guarulhos e outro homologado para a aeronave Embraer 145, em Curitiba. Todas os outros acreditados estão localizados no exterior, sendo aproximadamente $90 \%$ destes localizados nos Estados Unidos da América. São atualmente 37 tipos de aeronaves da aviação geral que possuem CTAC homologados pela ANAC e, somente um tipo tem um CTAC homologado no Brasil.

Devido à carência no Brasil, os operadores de aeronaves da aviação geral têm se deparado com uma série de barreiras para manter suas tripulações qualificadas, tanto econômicas quanto burocráticas, o que pode ser observado pelo número de licenças emitidas na Tab. (1) [5].

Tabela 1 - Licenças emitidas pela ANAC

\begin{tabular}{lccccc}
\hline Licenças & $\mathbf{2 0 1 2}$ & $\mathbf{2 0 1 3}$ & $\mathbf{2 0 1 4}$ & $\mathbf{2 0 1 5}$ & $\mathbf{2 0 1 6}$ \\
\hline PCM - PILOTO COMERCIAL - AVIAO & 1603 & 1714 & 1539 & 1281 & 1001 \\
PLA - PILOTO DE LINHA AEREA - AVIAO & 311 & 197 & 258 & 448 & 405 \\
PPR - PILOTO PRIVADO - AVIAO & 2938 & 2804 & 2403 & 2270 & 1724 \\
PCH - PILOTO COMERCIAL - HELICOPTERO & 495 & 753 & 614 & 319 & 181 \\
PPH - PILOTO PRIVADO - HELICOPTERO & 743 & 755 & 639 & 523 & 286 \\
PLH - PILOTO DE LINHA AEREA - HELICOPTERO & 134 & 167 & 153 & 80 & 41 \\
\hline
\end{tabular}

Fonte: ANAC, 2016.

Da tabela 1, destaque-se a diminuição da emissão de Licenças pela ANAC a partir de 2013 até 2016, sendo as mais afetadas as Licenças de Piloto Comercial de Helicóptero (PCH), com diminuição de aproximadamente $76 \%$, seguida pela queda de $75 \%$ para Piloto de Linha Aérea de Helicóptero (PLH) e 63\% para Piloto Privado de Helicóptero. As Licenças de Piloto Comercial de Avião (PCM) e Piloto Privado de Avião (PPR) caíram, respectivamente, $42 \%$ e $39 \%$, no mesmo período. Parece que, além da situação econômica no período, as novas exigências da ANAC contribuíram para esse quadro, especialmente a partir de 2015. 
A próxima seção apresenta as dificuldades encontradas para manter as tripulações qualificadas de acordo com as exigências da ANAC.

\subsection{Condições para o treinamento em CTAC}

Conforme comentado na seção anterior, a grande maioria dos pilotos deve se deslocar para os Estados Unidos da América (EUA) ou outros países a fim de realizarem seus treinamentos para a concessão ou revalidação de sua Habilitação de Tipo. Porém, para esse treinamento ser realizado, um processo longo e exaustivo deve ser iniciado com uma antecedência mínima de seis meses antes do vencimento da Habilitação, cuja validade é de 12 meses.

O primeiro passo é a necessidade de requerer um passaporte, e após deve-se aplicar para obter um visto americano, pois todo o processo de solicitação de treinamento exige que o profissional tenha visto válido para entrar nos EUA. Após a concessão do visto, deve ser solicitado para a autoridade americana responsável pela atividade aérea, o Transportation Security Administration (TSA) [13], a autorização para realizar treinamento nos EUA com antecedência mínima de 90 dias do início do treinamento. Em seguida a concessão da autorização, o piloto deve entrar em contato com um CTAC homologado e agendar seu treinamento. Para o treinamento em outros países, os procedimentos são idênticos, sendo a única diferença a necessidade de visto de entrada, dependendo do país a ser realizado o treinamento.

O custo médio de um treinamento para a concessão de Habilitação de Tipo nos EUA é de U\$ 25 mil por piloto e a duração média é de 14 dias [12]. Além do pagamento ao CTAC, o piloto deve pagar uma taxa à ANAC em vista da validação do processo, que no caso da concessão da Habilitação é de R $\$ 13.344,60$ [3]. Além dos custos do processo, há aqueles de: mobilidade, transporte, alimentação, diárias e hospedagem durante o período do treinamento, que ficam em torno de $30 \%$ do valor do treinamento.

Ao finalizar com sucesso o treinamento, o piloto encaminha toda a documentação para a ANAC, que analisará o processo e, em média de 21 dias, emitirá a Habilitação de Tipo.

Considerando que na grande maioria das aeronaves a tripulação é composta por dois pilotos, o custo com o treinamento obrigatório anual, devido à IS 61-005A, é de aproximadamente U $\$ 50$ mil dólares. Destacase que o proprietário da aeronave fica com a aeronave parada por aproximadamente 20 dias.

Comparando o valor do treinamento dos pilotos ao valor médio da hora de voo de uma aeronave a jato de pequeno porte como o Cessna Citation M2 que é de U\$1.395,36 [7], observamos o quanto é oneroso para os operadores atenderem as exigências da ANAC, já que o custo equivale a 35,86 horas de voo.

Considerando a burocracia da ANAC na análise dos processos, uma aeronave recém-adquirida, por exemplo, fica aproximadamente três meses parada, até que o processo de concessão de Habilitação dos pilotos e o processo de documentação da aeronave sejam concluídos, o que gera um custo operacional muito elevado e que, por vezes, faz o proprietário não querer investir em adquirir novas aeronaves ou desistir de possuí-las. Tais procedimentos, por parte da ANAC, são: a análise da documentação de compra da aeronave; emissão do Certificado de Aeronavegabilidade da aeronave; emissão do Certificado de Matrícula da aeronave; análise da documentação da realização do treinamento pelo piloto e emissão da Habilitação de Tipo para o piloto.

Tendo em vista a situação econômica do país, aliada aos entraves da agência reguladora, observa-se que o número de aeronaves que estão sem voar devido à falta de tripulantes qualificados está aumentando, o que vem prejudicando a aviação geral brasileira, contribuindo para a desaceleração e/ou estagnação da economia nacional, conforme mostra a fig. 4 [10]. 
Figura 4- Ranking de Aeródromos Brasileiros

\section{Ranking de Aeródromos - 2017}

(Pousos + Decolagens + Cruzamentos + TGL)

\begin{tabular}{|c|c|c|c|c|}
\hline & & & $\begin{array}{r}\text { Varic } \\
20\end{array}$ & $\begin{array}{l}\text { ção Anual } \\
6 / 2017\end{array}$ \\
\hline $1^{\circ}$ & Guarulhos & 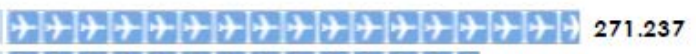 & $\boldsymbol{\nabla}$ & $-0,33 \%$ \\
\hline $2^{\circ}$ & Congonhas & 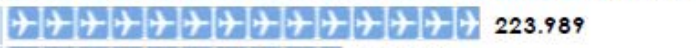 & $\mathbf{\Delta}$ & $1,93 \%$ \\
\hline $3^{\circ}$ & Brasilia & HHHAHHAHE 158.507 & $\boldsymbol{\nabla}$ & $-8,10 \%$ \\
\hline $4^{\circ}$ & Galeão & 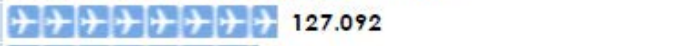 & $\boldsymbol{\nabla}$ & $-3,11 \%$ \\
\hline $5^{\circ}$ & Santos Dumont & HAthtith 118.149 & $\boldsymbol{\nabla}$ & $-1,76 \%$ \\
\hline $6^{\circ}$ & Campinas & HFHAHAH 112.772 & $\boldsymbol{\nabla}$ & $-5,36 \%$ \\
\hline $7^{\circ}$ & Confins & HAHAHA 100.593 & $\mathbf{\Delta}$ & $0,36 \%$ \\
\hline $8^{\circ}$ & Porto Alegre & HHHHA 83.377 & $\boldsymbol{\Delta}$ & $1,38 \%$ \\
\hline 90 & Campo de Marte & HAHEH 82.610 & $\boldsymbol{\nabla}$ & $-2,25 \%$ \\
\hline $10^{\circ}$ & Salvador & 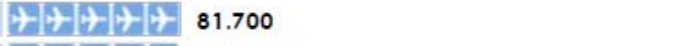 & $\boldsymbol{\nabla}$ & $-3,10 \%$ \\
\hline $11^{\circ}$ & Recife & HHAHA 79.169 & $\boldsymbol{\Delta}$ & $9,03 \%$ \\
\hline $12^{\circ}$ & Jacarepaguá & HAdAE 76.386 & $\boldsymbol{\Delta}$ & $5,40 \%$ \\
\hline $13^{\circ}$ & Curitiba & HAHAR 71.638 & $\boldsymbol{\Delta}$ & $2,29 \%$ \\
\hline $14^{\circ}$ & Goiânia & HAHA 66.247 & $\boldsymbol{\nabla}$ & $-2,06 \%$ \\
\hline $15^{\circ}$ & Fortaleza & HAHC 56.747 & $\boldsymbol{\nabla}$ & $-0,11 \%$ \\
\hline $16^{\circ}$ & Florianópolis & 거살 50.082 & $\boldsymbol{\nabla}$ & $-5,66 \%$ \\
\hline
\end{tabular}

Fonte: DECEA, 2018.

Visando a minimizar este cenário da aviação geral brasileira, na próxima seção é feita uma análise dos dados apresentados e apresentam-se sugestões para superar os entraves e dificuldades na aviação geral no Brasil.

\section{Resultados}

Com base nos dados apresentados nas seções anteriores e considerando-se que o Brasil possui a segunda maior frota de aeronaves mundial, destacam-se às seguintes condições:

a) a ANAC exige que os treinamentos para a concessão ou revalidação de Habilitação de Tipo sejam realizados em CTAC homologados ou validados;

b) no Brasil há somente dois CTAC homologado para 3 tipos de aeronave, entre as 37 listadas pela ANAC e a grande maioria dos CTAC estão nos EUA;

c) para a realização do treinamento em um CTAC nos EUA, o piloto deve ter visto de acesso ao país. O visto de acesso pode ser negado pelo país emissor, o que impossibilita a realização do treinamento;

d) o valor para a realização do treinamento anual dos pilotos é aproximadamente de U\$ 50 mil, o que encarece os custos operacionais do proprietário da aeronave;

e) a aeronave fica parada enquanto os pilotos realizam o treinamento e o processo é concluído pela ANAC;

f) a situação econômica do país é determinante para o número de aeronaves paradas por falta de tripulantes qualificados.

Com o intuito de viabilizar a atividade aérea no Brasil, sem diminuir os índices de segurança nas operações e visando uma redução de custos para os operadores de aeronave, sugere-se que a ANAC revise a IS 61005A e permita que os treinamentos de solo e de voo para a concessão e a revalidação de habilitação de tipo possam ser ministrados, temporariamente, por um piloto de linha aérea (PLA) qualificado e habilitado no 
modelo, como descrito nos itens 61.213 e 61.215 do RBAC n. ${ }^{\circ} 61$, para todos os tipos de aeronaves, até que existam CTAC's no Brasil, homologados ou validados para os treinamentos.

Esse treinamento, ministrado por um PLA, já era executado antes da mudança na instrução suplementar para todos os tipos de aeronave, observando o prescrito no item 61.213 , que abarca os pré-requisitos do candidato, os conhecimentos teóricos, o treinamento de solo e o de voo para a concessão da habilitação de tipo- e no item 61.215, instrumento obrigatório para renovação da habilitação de tipo.

Ressalte-se que, como a verificação e o exame de proficiência serão realizados pela ANAC, através dos Inspetores de Aviação Civil (INSPAC), fica garantida a qualidade da instrução, bem como a segurança nas operações. Esclareça-se que esses procedimentos foram ratificados ao longo de várias décadas na aviação brasileira. Acrescente-se, ainda, que tanto o candidato à habilitação como o PLA instrutor, serão avaliados pelo INSPAC, durante o exame de proficiência do piloto em instrução.

O aumento do número de tripulantes qualificados e, consequentemente, a elevação da quantidade de aeronaves voando, pois, com a redução dos custos para fazer o treinamento, de acordo com os itens 61.213 e 61.215, ambos do RBAC n. ${ }^{\circ} 61$, mais operadores investiriam na capacitação de suas equipagens.

Some-se, ainda, às sugestões acima, a realização de um estudo qualitativo sobre a viabilidade de criação de um centro de treinamento para a aviação geral no Brasil, levando-se em consideração a quantidade e os tipos de aeronaves em uso no país, bem como uma análise das ameaças e oportunidades de negócio, a qual servirá como base de apoio para futuros investidores em negócios da aviação.

Outra possibilidade seria a realização de uma consulta pública pela ANAC para coletar sugestões e feedbacks sobre os impactos causados pela nova legislação.

Na próxima seção apresenta, -se a conclusão deste trabalho e as perspectivas nas quais se confirma o impacto atual nas operações da aviação geral brasileira.

\section{Conclusão e perspectivas}

Um dos principais objetivos deste artigo foi realizar uma avaliação do atual cenário da aviação geral brasileira em relação ao cumprimento das novas exigências da ANAC para a concessão e a revalidação de habilitação de tipo, com ênfase para as razões, consequências e possíveis soluções para a crise que atinge fortemente esse segmento da aviação. Em particular, destaca-se a dificuldade do operador aéreo em manter suas tripulações devidamente qualificadas para a operação de suas aeronaves.

Conforme mostrado anteriormente, devido à falta de CTAC's no Brasil para atender a demanda dos tripulantes, é necessário que eles se dirijam ao exterior para realizar seus treinamentos, o que acarreta a elevação de custos para a operação das aeronaves, e está sendo um fator impeditivo para o crescimento da aviação geral.

É previsto, por meio das sugestões apresentadas, uma solução econômica e operacionalmente factível para o aumento do número de tripulações qualificadas, sem perda dos níveis de segurança operacional, através da realização dos treinamentos de solo e de voo por um PLA, somente enquanto não houver CTAC homologado no Brasil para atender todos os tipos de aeronave.

Também há o incentivo em fomentar instituições no Brasil a se habilitarem para realizar os treinamentos, o que, certamente, contribuirá para o aumento na segurança das operações, agregará valor de conhecimento especializado e colocará o país como um dos líderes mundiais em treinamento de tripulação.

Através do estudo de viabilidade econômica para a criação de um centro de treinamento para a aviação executiva, haverá uma contribuição significativa para o meio acadêmico, devido à inexistência de estudos relacionados ao tema.

Pode-se concluir, ainda, que se faz necessária uma revisão na legislação vigente, por parte da agência reguladora, com a finalidade de adequar os requisitos propostos por à realidade da aviação geral brasileira, 
sem haver, contudo, perda de qualidade na formação dos tripulantes, e com o intuito de elevar a segurança nas operações.

Tratar de segurança das operações na aviação é um tema sempre delicado, principalmente quando fatores como custos e operacionalidade são confrontados. Há de se considerar a máxima da segurança de voo: "Todo acidente pode e deve ser evitado" [9].

\section{Referências}

AGÊNCIA NACIONAL DE AVIAÇÃO CIVIL. Regulamento Brasileiro de Aviação Civil 61. Disponível em: http://www.anac.gov.br/assuntos/legislacao/legislacao-1/rbha-e-rbac/rbac/rbac-061-emd-06. Acesso em: 01 jul. 2017.

AGÊNCIA NACIONAL DE AVIAÇÃO CIVIL. Instrução Suplementar 61-005A. Disponível em: http://www. anac.gov.br/assuntos/legislacao/legislacao-1/iac-e-is/is/is-61-005a. Acesso em: 10 jul. 2017.

AGÊNCIA NACIONAL DE AVIAÇÃO CIVIL. Cheque Inicial Simulador (no exterior) ou Validação de Licença Estrangeira através de realização de provas no exterior. Brasília, 31 mar. 2017. Disponível em: http://www.anac.gov.br/servicos-de-referencia/gru/dadostfac-com-link-para-gru\#tab-chart_1_filters=\%7B $\% 22$ rowFilters \%22\%3A\%7B\%22ca3digo_da_tfac\%22\%3A\%5B\%225123\%22\%5D\%7D\%3B\%22columnFilters\% 22\%3A\%7B\%7D\%7D. Acesso em: 07 ago. 2017.

AGÊNCIA NACIONAL DE AVIAÇÃO CIVIL. Lista de Treinamento de Tipo aprovados pela ANAC. Brasília, 2 maio 2019. Disponível em: http://www2.anac.gov.br/Arquivos/pdf/Lista_de_Treinamentos_de_ Tipo.pdf. Acesso em: 16 ago. 2017.

AGÊNCIA NACIONAL DE AVIAÇÃO CIVIL. Pessoal da aviação civil. Disponível em: http://www.anac.gov. br/assuntos/dados-e-estatisticas/pessoal-da-aviacao-civil. Acesso em: 15 ago. 2017.

AGÊNCIA NACIONAL DE AVIAÇÃO CIVIL. Aeronaves. Brasília, 15 mar. 2016. Disponível em: http://www. anac.gov.br/assuntos/dados-e-estatisticas/aeronaves Acesso em: 16 jul. 2018.

AIRCRAFT OWNERS AND PILOTS ASSOCIATION. Hourly operating costs of 45 jets compared. Disponível em: https://www.aopa.org/news-and-media/all-news/2015/november/16/hourly-operating-costsof-45-jets-compared. Acesso em: 16 ago. 2017.

ASSOCIAÇÃO BRASILEIRA DE AVIAÇÃO GERAL (ABAG). Anuário brasileiro de aviação geral 2015. São Paulo: Shell, 2015. Disponível em: http://www.abag.org.br/anuario_aviacao/documents/Anuario_ Brasileiro_Aviacao_Geral_2015.pdf. Acesso em: 22 maio 2017.

CENTRO DE INVESTIGAÇÃO E PREVENÇÃO DE ACIDENTES AERONÁUTICOS. Normas do Sistema do Comando da Aeronáutica. NSCA 3-3 Gestão da Segurança de Voo na Aviação Brasileira.

Disponível em: http://www2.fab.mil.br/cenipa/index.php/legislacao/nsca-norma-do-sistema-do-comando-daaeronautica. Acesso em: 03 ago. 2017.

DEPARTAMENTO DE CONTROLE DO ESPAÇO AÉREO. Anuário estatístico de tráfego aéreo 2017. Rio de Janeiro: DCEA, 2018. Disponível em: http://portal.cgna.gov.br/files/uploads/anuario_estatistico/anuario_ estatistico_2017.pdf. Acesso em: 23 abr. 2018.

EMBRAER. Informações financeiras. Resultados 2015, 4T15. Disponível em: https://ri.embraer.com.br/ listresultados.aspx?idCanal=dwxMd7dcHTw/kwbNAc2ESQ==. Acesso em 12 jul. 2017.

FLIGHTSAFETY INTERNATIONAL. Disponível em: https://www.flightsafety.com/fs_service_aviation_ training_role.php?div=10\&code=C Acesso em: 25 jul. 2017. 
TRANSPORTATION SECURITY ADMINISTRATION. Department of Homeland Security. Disponível em: https://www.flightschoolcandidates.gov/afsp2/?acct_type=c\&section=WN Acesso em: 07 agosto 2017.

\section{Sobre os autores}

\section{Rodrigo Rodrigues de Carvalho Musy}

Graduado em Ciências Aeronáuticas/Oficial Aviador, Força Aérea Brasileira (AFA), Especialista em Segurança de Voo, Força Aérea Brasileira - CENIPA, Mestre em Segurança de Aviação e Aeronavegabilidade Continuada, Instituto Tecnológico de Aeronáutica (ITA).

\section{João César Moura Mota}

Graduado em Física, Universidade Federal do Ceará (UFC), Mestre em Engenharia Elétrica, Pontifícia Universidade Católica do Rio de Janeiro (PUC-RG), Doutor em Engenharia Elétrica, Universidade Estadual de Campinas (UNICAMP), Coordenador do curso de Graduação em Teleinformática, Universidade Federal do Ceará (UFC).

\section{Marcus Vinícius Garcia Pacobahyba Pessanha}

Graduado em Ciências Aeronáuticas/Oficial Aviador, Força Aérea Brasileira (AFA), Especialista em Segurança de Voo, Força Aérea Brasileira - CENIPA, Mestrando em Segurança de Aviação e Aeronavegabilidade Continuada, Instituto Tecnológico de Aeronáutica (ITA).

Recebido em: 21/08/2018

Aceito em: 30/04/2019 